\title{
Origen y evolución de las empresas Multilatinas
}

\author{
Mariano Merubia, José Emilio Navas-López ${ }^{1}$, Javier Amores-Salvadó, \\ Gregorio Martín-de Castro
}

Universidad Complutense de Madrid, España

doi: https://doi.org/10.20420/eni.2021.453

\begin{abstract}
Resumen
El estudio sobre el proceso de internacionalización de la empresa tradicionalmente se ha centrado en empresas multinacionales provenientes de países desarrollados, siendo minoritario su estudio en el contexto de países emergentes. En este trabajo analizamos los orígenes y evolución de las empresas multinacionales provenientes de América Latina, denominadas "Multilatinas", así como los especiales rasgos organizativos y estratégicos de las mismas, fruto de un contexto político, económico, social y cultural único latinoamericano.
\end{abstract}

Palabras clave: empresa multinacional, Latinoamérica, países en desarrollo, estrategia regional.

Clasificación JEL: M16, M14, M13.

Fuente de referencia: Avance del proyecto de Tesis Doctoral "Las Multilatinas y su Rentabilidad Mediante la Aplicación de Estrategias Medioambientales" realizada por el doctorando Mariano Merubia. Programa de Doctorado en Administración y Dirección de Empresas, Universidad Complutense de Madrid, España. Fecha de presentación: primer semestre de 2022.

\section{El fenómeno creciente de las empresas multinacionales de Latinoamérica}

El número de empresas multinacionales de países en desarrollo ha crecido considerablemente en los últimos tiempos, y éstas han irrumpido con gran fuerza en el escenario mundial. De acuerdo con la UNCTAD (2014) (Conferencia de las Naciones Unidas sobre Comercio y Desarrollo), las empresas multinacionales de los mercados emergentes ya representan una cuarta parte de todas las grandes multinacionales del mundo.

El interés académico sobre los mercados emergentes se comenzó a desarrollar en los años 2000, como resultado del cambio estructural que vio a las economías emergentes capturar una participación aparentemente creciente de la economía mundial, alcanzando más de la mitad del PIB global en 2012. La crisis del 2008 y la recesión económica originada en el continente europeo y en América del Norte hizo que los mercados de los países en desarrollo fueran más atractivos para los inversores. Como consecuencia, los inversores no pudieron ignorar que entre los años 2009 al 2013 estos mercados emergentes contribuyeron a la mayor parte del crecimiento económico global por primera vez desde la revolución industrial (Aguilera et al., 2017), contando con el $75 \%$ del territorio en el mundo, y representando cerca del $80 \%$ de la población mundial. Los llamados países del sur tienen una población mucho más joven y tienen bajos niveles de endeudamiento (Casanova, 2011).

En las últimas dos décadas, un grupo importante de multinacionales ha surgido de los países emergentes, especialmente de Asia y de Latinoamérica. Mientras que estas empresas han tenido comienzos humildes, algunas de ellas se han convertido en líderes globales (Guillén \& García-Canal, 2009). Por citar algunos ejemplos ilustrativos, la empresa mexicana CEMEX es líder mundial en la producción de cemento o la empresa argentina Tenaris es líder global en las

${ }^{1}$ Autor de correspondencia: jenavas@ccee.ucm.es. 
tuberías sin costuras. Las empresas multinacionales de los mercados emergentes tienen ciertas ventajas respecto a las multinacionales de los mercados desarrollados como, por ejemplo, los bajos costes de estructura o la experiencia de tratar con otros países con condiciones institucionales similares (Marano et al., 2017).

Se argumenta por una parte de la academia que la expansión internacional de las multinacionales de países emergentes se explica por el acceso privilegiado a una riqueza natural con características únicas y a la posibilidad de disponer de recursos humanos a bajo coste (Fleury et al., 2010). Asimismo, otros estudiosos sobre la internacionalización argumentan que dichas empresas multinacionales operan en el extranjero debido a la presencia en sus países de débiles instituciones, sistemas judiciales ineficientes, una regulación limitada, altos niveles de riesgo político, un débil control de la corrupción (Cuervo-Cazurra, 2008), y especialmente, una débil gobernanza corporativa.

La mayoría de las empresas Multilatinas término acuñado por Cuervo-Cazurra (2008) para referirse a las empresas multinacionales de origen de América Latina y el Caribe-, no se transformaron en multinacionales sino hasta inicios de la década del noventa, que es cuando los países de Latinoamérica abandonaron su política de industrialización mediante la sustitución de importaciones llevada a cabo a través de empresas estatales. Estos países abrieron sus economías a la competencia internacional $\mathrm{y}$ privatizaron sus empresas estatales. Dentro de este proceso y con el objeto de salvaguardar su autonomía, algunos estados latinoamericanos han fomentado empresas nacionales para convertirse en empresas multinacionales. Este tipo de política tuvo gran predicamento en Brasil, donde las empresas multinacionales se desarrollaron con acciones estatales directas, como por ejemplo el acceso a financiación otorgada por el Banco Nacional de Desarrollo (BNDES) (Finchelstein, 2017). Sirva como ejemplo de la aplicación de esta política lo que ocurrió con la empresa Vale, empresa que opera en los sectores de minería, logística, energía, siderurgia y petróleo, en donde el Gobierno de Brasil tiene influencia en el control de sus actividades mediante la posesión de la acción de oro.

Estas empresas latinoamericanas no son un grupo homogéneo, debido a que provienen de diferentes naciones e industrias, poseen $\mathrm{y}$ explotan diferentes ventajas competitivas, apuntan a diferentes mercados y países, y siguen diferentes caminos de internacionalización (Cuervo-Cazurra, 2008). Las empresas Multilatinas originalmente realizaban sus actividades en industrias básicas $\mathrm{y}$ manufactureras debido a las grandes cantidades de recursos naturales que poseían sus regiones de origen, y sin embargo, hoy en día, también incluyen dentro de sus actividades la creación de software, la industria petroquímica, y los servicios como las finanzas, transporte, bienes de consumo y comunicación. Entre las Multilatinas que desarrollan estas actividades podríamos mencionar a la empresa argentina Mercado Libre, que es la empresa líder en el comercio electrónico en toda Latinoamérica, a la empresa chilena Latam, que se dedica principalmente al transporte internacional de pasajeros, estando entre las diez empresas aéreas más importantes a nivel mundial, o el grupo mexicano Televisa, que es la empresa de medios de comunicación más importante en la región.

\section{Características de las empresas Multilatinas}

Latinoamérica es bastante homogénea y geográficamente aislada; está compuesta de muchos países con un contexto cultural, social, lingüístico, histórico, geográfico, económico, institucional y político similar (Cuervo-Cazurra, 2016). La región tiene unas claras 
particularidades comunes, como, por ejemplo, su pasado colonial, mayoritariamente español y portugués. A pesar de tener una enorme riqueza natural, existe una marcada diferencia en la distribución de los ingresos, lo que la convierte en una de las regiones con mayor desigualdad económico-social del planeta. Asimismo, también hay que destacar que las empresas pertenecientes a este contexto geográfico nacieron, crecieron y se desarrollaron en países en desarrollo caracterizados por: a) entornos inestables y disfuncionales, con vacíos institucionales que aumentan los costes de transacción, b) una pobre gobernanza corporativa, c) entornos de negocios en desventaja y d) elevados índices de incertidumbre (especialmente altos niveles de corrupción), y e) mayores riesgos políticos.

Las características de las Multilatinas son las siguientes (Rivera \& Soto, 2010):

- Propiedad del Estado o mixta: característica que continua presente en las multinacionales de América Latina y en las multinacionales de las economías emergentes (por ejemplo, la colombiana Ecopetrol SA y la argentina YPF SA).

- Propiedad Familiar: donde la búsqueda de la perdurabilidad es un elemento esencial y que implica que los objetivos perseguidos no son únicamente de carácter financiero, sino que van más allá. Sirva como ejemplo el caso de la empresa brasileña Gerdau SA o la mexicana Femsa (Duque-Grisales et al., 2019).

- Mayor flexibilidad en su gestión, lo que le permite adaptarse a diferentes situaciones en forma más rápida.

- Liderazgo fuerte y dinámico, con una visión a largo plazo.
- Habilidad de atender exitosamente a los mercados de bajos recursos. Para poder triunfar en la región se necesita atraer a la mayoría de la población con capacidad adquisitiva limitada, dado que el mercado con alto poder de compra es pequeño en Latinoamérica.

- Capacidad de innovación: debido a los diferentes problemas institucionales que enfrentan estas empresas, debieron desarrollar la innovación como un mecanismo de defensa, con el fin de mantenerse en el mercado.

No obstante, las Multilatinas tienen también otros elementos comunes. Así, provienen de economías de rápido desarrollo que han sido capaces de apoyar a fuertes empresas nacionales, poseen recursos de bajo coste como los recursos humanos o los bienes primarios, han crecido en entornos locales complicados y han tenido que hacer frente a la escasez de directivos especializados, entornos legales y financieros volátiles y sistemas logísticos y de infraestructura deficientes en sus países de origen. Todos los problemas que enfrentaron las Multilatinas ayudaron a su transformación en empresas altamente ágiles e innovadoras.

A pesar de las similitudes destacadas, las Multilatinas no tienen un único patrón de internacionalización. Fleury et al., (2010) enfatizaron que las empresas multinacionales emergentes y particularmente las Multilatinas han usado múltiples modos de entrada para expandirse internacionalmente y que, por ello, los patrones de internacionalización difieren de uno a otro. Esto se debe al hecho de que el proceso de multinacionalización de cada una de ellas ha sido influenciado por su propio contexto y condiciones. Hoy en día, la nueva tendencia es que las Multilatinas entren tanto a mercados desarrollados como menos desarrollados simultáneamente (Guillén \& García-Canal, 2009). 
Available online at https://ojsspdc.ulpgc.es/ojs/index.php/ENI

\section{El grado de internacionalización de las Multilatinas}

Latinoamérica representa cerca de la tercera parte de las economías en desarrollo en términos de PIB y está situada en el segundo lugar entre las regiones de economía emergente después de Asía-Pacífico. Sin embargo, el proceso de desarrollo de los países de Asía Pacífico está fuertemente formado por sus sectores industriales, mientras que en los países de Latinoamerica están tradicionalmente basado en la exportación de los comodities de los recursos naturales (Hermans \& Reyes, 2020).

Los factores impulsores que indujeron a las empresas Multilatinas a convertirse en empresas multinacionales fueron los cambios en las condiciones institucionales bajo las cuales operaban (Cuervo-Cazurra, 2008). Entre ellas pueden destacarse el limitado crecimiento potencial en los mercados nacionales, la diversificación del riesgo especifico país o la búsqueda del aprendizaje organizativo para aumentar la competitividad en los mercados nacionales o extranjeros. Igualmente, el apoyo de los Gobiernos nacionales mediante las políticas industriales también puede considerarse como un elemento impulsor de la internacionalización de las Multilatinas.

La mayoría de las Multilatinas sigue siendo de naturaleza altamente regional, lo que ayuda a explicar por qué no son más reconocidas a nivel mundial. Durante los años 1990 y 2000 estas empresas iniciaron o aceleraron su proceso de internacionalización, pero principalmente dirigiéndose a mercados que fuesen geográficamente cercanos. Esto es consistente con los argumentos, entre otros, de Rugman y Verbeke (2004), quienes afirmaron que la mayoría de las Multilatinas tienden a crecer internacionalmente principalmente dentro de su propia región de origen. La expansión regional de las empresas de Latinoamerica, no solo es regional en términos de dirigirse hacia América
Latina, sino que dentro de esa tendencia general, también se crean además espacios más específicos de interacción o sub regiones, por lo que es común, por ejemplo, que las empresas multinacionales sudamericanas tiendan a operar en el mercado de América del Sur, ignorando expandirse al mercado mexicano $o$ al centroamericano (Aguilera et al., 2017), como es el caso de empresa chilena Falabella, que es la tienda por departamentos más grande y valiosa de América Latina, y que sólo opera en Chile, Perú y Colombia. En este sentido, también puede apreciarse que las Multilatinas mexicanas tienen una estrategia de internacionalización distintiva en comparación con las otras Multilatinas debido a su acceso a los mercados desarrollados de Norteamérica, apoyado en el acceso de México al Tratado entre México, Estados Unidos y Canadá (T-MEC).

Otras explicaciones para dicha regionalidad es la familiaridad con el lenguaje de negocios, las redes personales, y las costumbres similares de los clientes (Vélez-Ocampo et al., 2017). En términos generales, la expansión exitosa de las Multilatinas comienza con los mercados geográficamente próximos, llamados mercados naturales, con los que comparten el lenguaje y su bagaje histórico (Casanova, 2011). Estos mercados naturales tienen como característica que es más fácil la circulación de información, permitiendo un mayor conocimiento de la situación competitiva del mercado, una mayor conexión en red y un mismo lenguaje que abre la posibilidad a mejores relaciones comerciales.

Entre las causas subyacentes de la escasez de Multilatinas con orientación global se pueden encontrar las políticas proteccionistas (como la aplicación del modelo de sustitución de importaciones que dominó la mayor parte del siglo XIX), las numerosas barreras arancelarias impuestas, los consumidores locales cautivos, los débiles mercados de capitales regionales, los bajos niveles de inversión en las actividades de I+D y la existencia de entornos políticos e 
institucionales complejos e impredecibles (Casanova, 2011).

Por su parte, las empresas latinoamericanas que sí han sido capaces de surgir globalmente fueron aquellas que reaccionaron y se ajustaron exitosamente a las presiones externas, ya sea presiones positivas y negativas, que pusieron a prueba sus instintos de supervivencia y capacidades de innovación. Estas presiones enseñaron a las empresas latinoamericanas a navegar a través de aguas turbulentas, resistir y gestionar el riesgo gracias a sus habilidades específicas para la ejecución de proyectos, su capacidad para entablar redes nacionales e internacionales, y adaptarse a las debilidades institucionales e inestabilidad política de sus países (Cuervo-Cazurra \& Ramamurte, 2013).

\section{Conclusiones}

Aunque Latinoamérica es una región poco investigada académicamente, tiene el potencial de generar nuevo conocimiento sobre los negocios internacionales en los mercados en desarrollo. Efectivamente, las Multilatinas se han formado en pobres condiciones institucionales en sus países de origen y con el objetivo de superar estas dificultades han empezado a operar en los mercados internacionales.

Las operaciones internacionales de las Multilatinas al principio siguieron la corriente de la internacionalización regional dentro de América Latina, pero en la actualidad se encuentran orientadas a nivel global y tienen actividades tanto en países en desarrollo como en países desarrollados. Así, las perspectivas actuales y futuras son prometedoras, no sólo dedicándose a la exportación de "comodities" provenientes de recursos naturales, sino que también incluyen actividades de mayor valor agregado, como es el caso emblemático de la empresa brasileña Embraer, que con la ayuda del Estado se convirtió en uno de los tres principales fabricantes de aeronaves en el mundo, operando en un sector de alta complejidad tecnológica que ha estado tradicionalmente reservado para las empresas de países desarrollados.

La incursión en nuevas actividades más sofisticadas, dejando a un lado la clásica exportación de productos primarios, viene acompañada de un periodo caracterizado por un rendimiento económico positivo y mayor visibilidad de la región, lo que les otorga a estas empresas una gran fortaleza. Fruto de este nuevo tiempo se está produciendo gradualmente la inclusión de las economías latinoamericanas en diferentes organismos internacionales, ya sean formales o informales. Este es el caso de Brasil, que fue incluida dentro de los países BRICS, consideradas como las economías de los nuevos poderes económicos emergentes del mundo, junto con Rusia, India, China y Sudáfrica (Ciravegna et al., 2014), o el caso de México y Colombia, que también fueron incluidos en otros grupos representativos de las economías emergentes de más rápido crecimiento como son el MIKTA (México, Indonesia, Corea del Sur, Turquía, y Australia) y el CIVETS (Colombia, Indonesia, Vietnam, Egipto, Turquía y Sudáfrica), respectivamente.

\section{Referencias}

Aguilera, R.V., Ciravegna, L., Cuervo-Cazurra, A., \& González-Pérez, M.A. (2017). Multilatinas and the internationalization of Latin American firms. Journal of World Business, 52(4), 447-460. Doi: 10.1016/j.jwb.2017.05.006

Casanova, L. (2011). El ascenso de las multilatinas en la economía mundial. Información Comercial Española, 859, 21-31.

CEPAL (2015). La inversión extranjera directa en América Latina y el Caribe. Santiago de Chile: Editorial Cepal.

Ciravegna, L., López, L., \& Kundu, S. (2014). Country of origin and network effects on internationalization: A comparative study of SMEs from an emerging and developed economy. Journal of 
Business Research,67(5), 916-923. Doi: Marano, V., Tashman, P., \& Kostova, T. (2017). 10.1016/j.jbusres.2013.07.011

Escaping the iron cage: Liabilities of origin and CSR

Cuervo-Cazurra, A. (2008). The multinationalization of developing country MNEs: The case of Multilatinas. Journal of International Management, 14(2), 138-154. Doi: 10.1016/j.intman.2007.09.001.

Duque-Grisales, E., Aguilera-Caracuel, J., GuerreroVillegas, J., \& García-Sánchez, E. (2019). Can proactive environmental strategy improve Multilatinas' level of internationalization? The moderating role of board Independence. Business Strategy and the Environment, 29(1), 291-305. Doi: 10.1002/bse.2377.

Finchelstein, D. (2017). The role of the State in the internationalization of Latin American firms. Journal of World Business, 52(4), 578-590. Doi: 10.1016/j.jwb.2017.04.003.

Fleury, A., Fleury, M.T.L., \& Reis, G.G. (2010). El camino se hace al andar: La trayectoria de las multinacionales brasileñas. Universia Business Review, 25, 34-55.

Guillén, M.F., \& García-Canal, E. (2009). The American model of the multinational firm and the new multinationals from emerging economies. Academy of reporting of emerging market multinational enterprises. Journal of International Business Studies, 48(3), 386-408. Doi: 10.1057/jibs.2016.17.

Rivera Notario, R., \& Soto Marifil, R. (2010). Empresas Multilatinas: caracterización y examen de casos de interés. Santiago de Chile: Repositorio Facultad de Economía y Negocios, Universidad de Chile.

Rugman, A.M., \& Verbeke, A. (2004). A perspective on regional and global strategies of multinational enterprises.Journal of International Business Studies, 35(1), 3-18. Doi: 10.1057/palgrave.jibs. 8400073 .

UNCTAD (2014). World investment report 2014: FDI from developing and transition economies: Investing in the SDGS: An action plan. Nueva York: Naciones Unidas.

Vélez-Ocampo, J., Govindan, K., \& González-Pérez, M.A. (2017). Internationalization of Mexican family firms: the cases of Xignus and Grupo Alfa. Review of International Business and Strategy, 27(2), 180-198. Doi: 10.1108/RIBS-10-2016.

Management Perspectives, 23(2), 23-35. Doi: 10.5465/amp.2009.39985538. 